\title{
PHYSICAL ACTIVITY, MOTOR COMPETENCE, AND PERCEIVED PHYSICAL COMPETENCE: WHAT IS THEIR RELATIONSHIP IN CHILDREN AGED 6-9 YEARS?
}

original paper

( ) University School of Physical Education in Wrocław

DOI: https://doi.org/10.5114/hm.2018.73612

\section{ANASTASIA-EVANGELIA AFTHENTOPOULOU ${ }^{1}$, FOTINI VENETSANOU ${ }^{1}$, AIKATERINI ZOUNHIA ${ }^{1}$, KONSTANTINOS PETROGIANNIS ${ }^{2}$}

\author{
${ }^{1}$ School of Physical Education and Sport Science, National and Kapodistrian University of Athens, Athens, Greece \\ ${ }^{2}$ Hellenic Open University, Patras, Greece
}

\begin{abstract}
Purpose. This study investigated the association between physical activity (PA), motor competence (MC), and perceived physical competence (PPC) in 56 boys and 65 girls aged 6-9 years.

Methods. PA was recorded by Omron HJ-720IT pedometers, MC was assessed with the Bruininks-Oseretsky Test of Motor Proficiency, second edition, and PPC was determined with the physical competence subscale of the Pictorial Scale of Perceived Competence and Social Acceptance for Young Children, Greek version.

Results. ANCOVA (with age as a covariate) revealed that boys were significantly more active than girls. Correlations among PA, MC, and PPC were not significant in either gender.

Conclusions. It seems that between 6 and 9 years of age, the relation among PA, MC, and PPC has not been formed yet. This age range is offered for interventions targeting these factors in order for their relationship to be enhanced later in life. However, further research for the investigation of other variables that may associate with PA at this age is needed.
\end{abstract}

Key words: pedometers, motor skills, self perception, childhood

\section{Introduction}

With the need to increase the levels of physical activity (PA) during childhood being urgent [1], several researchers have investigated the factors associated with children's PA participation. Gender seems to differentiate children's PA levels, with boys being more active than their female peers [e.g., 2-4]. However, in both genders, age appears to play a significant role too, as research findings suggest that PA levels are increased in 5-9-year-olds, whereas after the age of 10 there is a decrease, which becomes bigger in adolescence [5].

If PA declines in late childhood and adolescence are to be diminished, the first years of school age (6-9 years) are very important for the establishment of a physically active lifestyle through enhancing PA correlates. Among these correlates, motor competence (MC) seems to be a critical one. Several studies have found a positive relationship between $\mathrm{PA}$ and $\mathrm{MC}$ in children and youth aged 5-16 years [e.g., 6-11], with more competent children participating in higher levels of PA and less skilled children avoiding PA, perhaps owing to a hypothetical 'proficiency barrier' that they face [12]. However, this issue has been investigated to a limited extent in children aged 6-9 years $[2,4,10$, $11,13,14]$, with the majority of studies revealing a significant association between PA and MC at this specific age $[10,11,13,14]$.

Another key correlate of PA is children's perception of their physical competence. Higher levels of perceived physical competence (PPC) have been found to positively associate with increased PA in children [e.g., 3] and youth [e.g., 15]. However, for school age children, research findings are few and conflicting, with some studies having detected a significant relationship between PA and PPC [16] and some other not [2, 4, 13].

Concerning the relationship between PA, MC and

Correspondence address: Anastasia-Evangelia Afthentopoulou, School of Physical Education and Sport Science, National and Kapodistrian University of Athens, Ethnikis Antistasis 41, Dafni 17237, Greece, e-mail: anastafth@phed.uoa.gr

Received: September 14, 2017

Acepted for publication: November 13, 2017

Citation: Afthentopoulou A-E, Venetsanou F, Zounhia A, Petrogiannis K. Physical activity, motor competence, and perceived physical competence: what is their relationship in children aged 6-9 years?. Hum Mov. 2018;19(1):51-56; doi: https://doi. org/10.5114/hm.2018.73612. 
A-E. Afthentopoulou, F. Venetsanou, A. Zounhia, K. Petrogiannis, Physical activity and competence in children

PPC, according to the theoretical model of Stodden et al. [17], PPC acts as a mediator in the association between $\mathrm{PA}$ and MC, with a child of a high MC level demonstrating greater PA if their PPC is positive. This hypothesis has been confirmed by some researchers [18]; nevertheless, only a limited number of studies have focused on children between $6-9$ years of age [2-4, 13], and their results are inconsistent. Specifically, in the study by Barnett et al. [2], the relationship between MC and PA, as well as between PPC and PA, was found to be insignificant in children aged $5-8$ years $(n=102)$, whereas the relationship between PPC and MC turned out significant. Similar were the findings of Slykerman et al. [4], who examined these relationships in 109 children aged 5-7 years. On the other hand, Wrotniak et al. [13] and De Meester et al. [3], who also report a significant association between PPC and MC in 8-10-year-old children $(n=65$ and $n=361$, respectively), found a significant relationship between MC and PA, whereas only De Meester et al. [3] revealed a significant association between PPC and PA.

In this context, it becomes obvious that the relationship between PA, MC, and PPC in school-aged children is not clear, as research evidence is quite limited and the results are rather ambiguous. The investigation of this relationship in that age period will shed light into PA correlates and may contribute to better understanding of children's PA behaviours. The aim of the present cross-sectional study was to investigate the relationship between PA, MC, and PPC in boys and girls aged 6-9 years.

\section{Material and methods}

\section{Participants}

The total of 145 children aged 6-9 years living in Athens (Greece) volunteered to participate in the study. Their parents (or legal guardians) signed a written informed consent before the children's participation in the study. The research was conducted in accordance with the Declaration of Helsinki. From among the above participants, 121 (56 boys and 65 girls; mean age $=7.6$ years, $S D=0.9$ ) provided valid pedometer data and completed all assessments, thus their data were used for the statistical analyses.

\section{Measures}

\section{Physical activity}

The participants' PA was recorded with the use of Walking Style Pro HJ-720IT-E2 (HJ-720) Omron pedometers over 7 consecutive days. The average daily steps were considered in the study. The Omron HJ-720 pedometer has been found to accurately record ambulatory activity in children [19].

\section{Motor competence}

The Bruininks-Oseretsky Test of Motor Proficiency, second edition, Short Form (BOT-2SF) [20] was used to evaluate the children's actual MC. The BOT-2 is a widely used, well-validated, standardized, normreferenced measure of fine and gross motor skills of children and youth aged 4-21 years [20]. It consists of the following 14 items: drawing lines through paths, crooked; folding paper; copying a square; copying a star; transferring pennies; dropping and catching a ball; dribbling a ball; jumping in place, same sides synchronized; tapping feet and fingers; walking forward on a line; one-legged stationary hop; standing on one leg on a balance beam - eyes open; knee push-ups; situps. Its administration lasts approximately 25-30 minutes. An examinee's performance on the BOT-2SF can be reported as a total point score, standard score, percentile rank, or in descriptive categories. In the present study, the total BOT-2SF point score was applied. Regarding the BOT-2SF psychometric characteristics in the Greek population, there is enough evidence supporting both its validity and reliability [21].

\section{Perceived physical competence}

The physical competence subscale of the Pictorial Scale of Perceived Competence and Social Acceptance for Young Children (PSPCSA) [22] was used to assess the participants' PPC. This subscale determines the children's perception of their competence when performing 5 skills (running, climbing, bouncing a ball, swinging, horizontal bar), which are presented to children through sex-specific drawings. For each skill, 2 drawings illustrating opposite skill performance (competent and poor) are presented. First, the child is asked which drawing is like him or her, and then they rate their performance as 'really good' or 'pretty good' (for competent performance) and 'sort of good' or 'not that good' (for poor performance). Responses are rated on a 4 -point Likert scale ranging from 1 (low PPC) to 4 (high PPC). The subscale score is the mean of the 5 item scores. The administration of the PSPCSA-physical competence subscale lasts approximately 5-7 minutes.

The validity and reliability of the PSPCSA have been examined by its authors [22]. In the present study, the Greek version of the scale was used [23], which presents adequate psychometric characteristics [23]. 


\section{Procedure}

The administration of both BOT-2SF and PSPCSA took place on an individual basis, according to the specific guidelines [20,23]. The examiner was experienced in dealing with the BOT-2 and PSPCSA and familiar with motor and self-perception assessment in general. In order to avoid the participants' PPC to be affected by their performance on the BOT-2SF, the assessment of MC followed that of PPC.

After the completion of the above measurements, children were given the pedometers along with written information and instructions for their appropriate use. Before usage, the pedometers were all tested and demonstrated $<3 \%$ error on a walk test and $<1 \%$ error on a shake test [24]. Each pedometer was fitted at the child's right hip every day after waking up and dressing, and was removed when the child was sleeping, bathing, or swimming. Parents were asked to ensure that their children wore the pedometers as long as possible during the day, for 7 consecutive days. If a child forgot to wear their pedometer, they were instructed to wear it on the following day. The 7-day evaluation period is recommended as a sufficient length of time for determining children's PA levels [25].

\section{Statistical analyses}

Average pedometer counts were calculated for two time periods: (a) weekdays: average step counts for at least 3-weekday data, and (b) weekend: average step counts for Saturday and Sunday data. Pedometer scores below 1000 and above 30,000 were not included in the analyses as they were identified as outlying scores.

According to Shapiro-Wilk's tests and/or box plots, data were normally distributed. A one way ANCOVA was used to determine possible differences in PA between girls and boys, including age as a covariate. Apart from $p$ values, effect size was also examined with $\eta^{2}$ for data interpretation, following Cohen's [26] guidelines $\left(\eta^{2}\right.$ values smaller than 0.06 are considered small, those between 0.06 and 0.13 are considered medium, and those higher than 0.14 are considered large). Pearson product-moment correlation $(r)$ was applied to examine potential correlations between the children's average daily steps (PA), the total BOT-2SF point score (MC), and the PSPCSA-physical competence subscale score (PPC).

As statistically significant differences were revealed between the PA of boys and girls, Pearson productmoment correlations were computed for each gender separately. Statistical analyses were performed with the use of the IBM SPSS Statistics 22.0 and alpha level was set at 0.05 .

\section{Ethical approval}

The research related to human use has been complied with all the relevant national regulations and institutional policies, has followed the tenets of the Declaration of Helsinki, and has been approved by the authors' institutional review board.

\section{Informed consent}

Informed consent has been obtained from all individuals included in this study.

\section{Results}

Table 1 provides descriptive statistics aggregated by sex for age, PA, MC, and PPC. It can be noticed that boys accumulated more daily steps than girls; however, they had almost the same mean MC score, which was high (taking into account that BOT-2SF assesses MC of children and youth aged 4-21 years). This reveals that both boys and girls were proficient movers. Moreover, boys demonstrated a slightly higher PPC mean compared with girls, with the values proving that the participants held relatively positive perception of their physical competence.

Table 1. Descriptive statistics of age, physical activity, motor competence, and perceived physical competence

\begin{tabular}{lcccccc} 
& \multicolumn{2}{c}{ Total $(n=121)$} & \multicolumn{2}{c}{ Boys $(n=56)$} & \multicolumn{2}{c}{ Girls $(n=65)$} \\
\cline { 2 - 7 } & Mean & $S D$ & Mean & $S D$ & Mean & $S D$ \\
\hline Age (years) & 7.6 & 0.9 & 7.69 & 0.95 & 7.56 & 0.91 \\
Physical activity (steps/day) & 11,600 & 3564 & 13,365 & 3514 & 10,106 & 2872 \\
Motor competence (BOT-2SF total point score [0-88]) & 59.59 & 7.25 & 59.24 & 8.80 & 59.91 & 6.30 \\
Perceived physical competence (PSPCSA-physical & \multirow{2}{*}{3.41} & 0.49 & \multirow{2}{*}{3.48} & 0.47 & 3.34 & 0.50 \\
competence subscale score [1-4]) & & & & & & \\
\hline
\end{tabular}

BOT-2SF - Bruininks-Oseretsky Test of Motor Proficiency, second edition, Short Form,

PSPCSA - Pictorial Scale of Perceived Competence and Social Acceptance for Young Children 
A-E. Afthentopoulou, F. Venetsanou, A. Zounhia, K. Petrogiannis, Physical activity and competence in children

According to the ANCOVA results, age was not related to the children's PA $(p=0.34)$, whereas the effect of gender was statistically significant $\left(F_{1,118}=29.94\right.$, $p<0.001, \eta^{2}=0.20$ ), favouring boys, with the value of $\eta^{2}$ revealing that this difference was of practical importance.

Pearson's bivariate correlational results indicated that there were no statistically significant correlations among variables either in boys $\left(r_{\mathrm{PA}-\mathrm{MC}}=0.059, p=0.671\right.$; $\left.r_{\mathrm{PA}-\mathrm{PPC}}=0.156, p=0.255 ; r_{\mathrm{MC}-\mathrm{PPC}}=0.060, p=0.635\right)$ or in girls $\left(r_{\mathrm{PA}-\mathrm{MC}}=-0.037, p=0.767 ; r_{\mathrm{PA}-\mathrm{PPC}}=0.065\right.$, $\left.p=0.604 ; r_{\mathrm{MC}-\mathrm{PPC}}=0.160, p=0.163\right)$.

\section{Discussion}

The aim of this study was to examine the relationship between PA, MC, and PPC in boys and girls aged 6-9 years. Starting with a closer look at the participants' PA, the results revealed that although boys succeeded to gather the daily PA that is necessary for their health (13,000-15,000 steps/day) [27], girls' PA was lower than it is recommended (11,000-13,000 steps/day) [27]. Moreover, boys were significantly more physically active than girls, a finding that is in line with a growing body of research [e.g., 2-4]. These significant differences in PA favouring boys could be, in part, explained by the cultural context [28], in which both genders may be forced into their stereotyped roles, avoiding specific activities [29]. According to several studies, boys engage in more vigorous-intensity activities involving greater amounts of body contact than girls and play in larger groups in more open settings [30]. In contrast, girls prefer socializing with friends and taking part in low-intensity activities, like hopscotch [30]. Taking into consideration that PA declines after the age of 10 years [5], it is obvious that efforts to increase the participation of girls aged 6-9 years in PA should be forced. To that direction, developmentally appropriate PA opportunities in primary schools could be embedded in the curriculum to ensure that no child is excluded from PA.

Concerning the association between PA and its correlates, starting with $\mathrm{MC}$, according to the theoretical model of Stodden et al. [17], PA and MC are weakly related in young children, whereas their relationships become more significant and strengthen in middle childhood (7-9 years) and adolescence. The above hypothesis has been confirmed by research findings that revealed weak correlations between PA and MC in preschool children [31] and moderate to strong in adolescents [6]. The present results showed that the correlation between those two variables was nonsig- nificant in 6-9-year-old children, either boys or girls. Similar were the conclusions of both Barnett et al. [2] and Slykerman et al. [4] in children aged 5-8 years and 5-7 years, respectively.

However, this study contrasts with previous research that has found MC to be associated with PA in school aged children [e.g., 7-11, 13, 14, 32]. Nevertheless, in some of these studies, PA was measured with subjective (self-reported) tools $[10,11]$ or a wider age range was included [7-9, 32], making the comparison of their findings with the present ones difficult.

The nonsignificant relationship between PA and MC in the current study, despite the participants' high MC level, can perhaps be explained by the fact that PA in that age stems from playful activities which may not require a high $\mathrm{MC}$ level; as children age, a larger amount of PA may come from sport-related activities [2]. Moreover, it should be taken into account that in this young age, parents determine children's PA participation [33].

In the current study, a nonsignificant relationship between PA and PPC was revealed. This finding is in line with previous studies in children [2, 4, 13]; however, it remains in contrast with other studies, which report a significant association of PPC with PA [3, 16]. Nevertheless, it should be noted that in those studies, different aspects of the multidimensional structure of PPC [34] were examined, such as perceived physical appearance, perceived physical performance, and perceived physical fitness. Consequently, comparisons with our findings should be made with caution. The lack of association between PA and PPC in the present study is probably caused by the participants' high positive perception of their competence [35].

Finally, a nonsignificant relationship between the children's MC and PPC was also revealed. This finding is in close agreement with the observations of Spessato et al. [36], but only with reference to the age of 7 years, and remains in contrast with other studies $[2,13,37]$. Perhaps it is the participants' very positive perception of their physical competence that contributed to the lack of association between MC and PPC. It is well known that young children (almost until the age of 8) tend to have inflated perception of their physical competence [38], as it is difficult for them to distinguish between their efforts and the results of their actions [38].

This study has some limitations that should be taken into account when interpreting its findings. To begin with, its cross-sectional design, as well as the relatively small sample weaken its findings. Secondly, although pedometers provide objective information 
about PA, they cannot assess specific physical activities (e.g., cycling, swimming) or PA intensity, in this way restricting information about the actual PA. Besides its limitations, however, the study, by combining objective PA data with children's performance on two widely used assessment tools (BOT-2SF and PSPCSA), sheds light on an interesting issue that has not been fully investigated yet.

The absence of significant correlations among MC, PPC, and PA in children aged 6-9 years observed in this study indicates that their association may not have been formed yet. However, the enhancement of both PPC and MC at this age is important. Starting with the MC, its significant role for PA participation later in life has been well documented [39, 40], so encouraging a high MC level in childhood is of great importance. Also essential is the promotion of children's confidence and enjoyment during PA to ensure that their positive PPC will maintain later in life [15]. However, further research for the investigation of other variables (e.g., parent PA, parent overweight/obesity, parental encouragement, family socioeconomic status) that may associate with PA at this age is needed if PA participation is to be fully understood.

\section{Conclusions}

The results of this study indicate that the relationship among PA, MC, and PPC in children aged 6-9 years seems to have not been formed yet. Since the association among these three variables is thought to strengthen as children get older [17], the age period between 6 and 9 years appears to be 'a window of opportunity' for enhancing MC and maintaining positive PPC in order for their association with PA to be positive in adolescence and adulthood, as well as for lifetime PA participation to be achieved.

\section{Disclosure statement}

No author has any financial interest or received any financial benefit from this research.

\section{Conflict of interest}

The authors state no conflict of interest.

\section{References}

1. World Health Organization. Report of the commission on ending childhood obesity. Geneva: WHO Document Production Services; 2016.

2. Barnett LM, Ridgers ND, Salmon J. Associations between young children's perceived and actual ball skill competence and physical activity. J Sci Med Sport.
2015;18(2):167-171; doi: 10.1016/j.jsams.2014.03.001.

3. De Meester A, Stodden D, Brian A, True L, Cardon G, Tallir I, et al. Associations among elementary school children's actual motor competence, perceived motor competence, physical activity and BMI: a cross-sectional study. PLoS One. 2016;11(10):e0164600; doi: 10.1371/journal.pone.0164600.

4. Slykerman S, Ridgers ND, Stevenson C, Barnett LM. How important is young children's actual and perceived movement skill competence to their physical activity? J Sci Med Sport. 2016;19(6):488-492; doi: 10.1016/j. jsams.2015.07.002.

5. Craig CL, Cameron C, Tudor-Locke C. CANPLAY pedometer normative reference data for 21,271 children and 12,956 adolescents. Med Sci Sports Exerc. 2013;45(1):123-129; doi: 10.1249/MSS.0b013e3182 $6 a 0 f 3 a$.

6. Hardy LL, O’Hara BJ, Rogers K, St George A, Bauman A. Contribution of organized and nonorganized activity to children's motor skills and fitness. J Sch Health. 2014;84(11):690-696; doi: 10.1111/josh.12202.

7. Spessato BC, Gabbard C, Valentini NC. The role of motor competence and body mass index in children's activity levels in physical education classes. J Teach Phys Educ. 2013;32(2):118-130; doi: 10.1123/jtpe.32.2.118.

8. Barnett LM, van Beurden E, Morgan PJ, Brooks LO, Beard JR. Childhood motor skill proficiency as a predictor of adolescent physical activity. J Adolesc Health. 2009;44(3):252-259; doi: 10.1016/j.jadohealth.2008. 07.004 .

9. Ziviani J, Poulsen A, Hansen C. Movement skills proficiency and physical activity: a case for Engaging and Coaching for Health (EACH)-Child. Aust Occup Ther J. 2009;56(4):259-265; doi: 10.1111/j.1440-1630.2008. 00758.x.

10. Lopes VP, Rodrigues LP, Maia JA, Malina RM. Motor coordination as predictor of physical activity in childhood. Scand J Med Sci Sports. 2011;21(5):663-669; doi: 10.1111/j.1600-0838.2009.01027.x.

11. Chen W, Hammond-Bennett A, Mason S, Hypnar A. Motor skill competency and physical activity in elementary school students. Int J Hum Soc Sci Educ. 2015; 2(4):76-83.

12. Seefeldt V. Developmental motor patterns: implications for elementary school physical education. In: Nadeau CH, Halliwell W, Newell K, Roberts G (eds.), Psychology of motor behavior and sport. Champaign: Human Kinetics; 1980; 314-323.

13. Wrotniak BH, Epstein LH, Dorn JM, Jones KE, Kondilis VA. The relationship between motor proficiency and physical activity in children. Pediatrics. 2006;118(6): e1758-e1765; doi: 10.1542/peds.2006-0742.

14. Cohen KE, Morgan PJ, Plotnikoff RC, Callister R, Lubans DR. Fundamental movement skills and physical activity among children living in low-income communities: a cross-sectional study. Int J Behav Nutr Phys Act. 2014;11(1):49-57; doi: 10.1186/1479-5868-11-49. 
A-E. Afthentopoulou, F. Venetsanou, A. Zounhia, K. Petrogiannis, Physical activity and competence in children

15. Timo J, Sami YP, Anthony W, Jarmo L. Perceived physical competence towards physical activity, and motivation and enjoyment in physical education as longitudinal predictors of adolescents' self-reported physical activity. J Sci Med Sport. 2016;19(9):750-754; doi: 10.1016/j.jsams.2015.11.003.

16. Planinšec J, Fošnarič S. Relationship of perceived physical self-concept and physical activity level and sex among young children. Percept Mot Skills. 2005;100(2):349_ 353; doi: 10.2466/PMS.100.2.349-353.

17. Stodden DF, Goodway JD, Langendorfer SJ, Roberton MA, Rudisill ME, Garcia C, et al. A developmental perspective on the role of motor skill competence in physical activity: an emergent relationship. Quest. 2008;60(2): 290-306; doi: 10.1080/00336297.2008.10483582.

18. Barnett LM, Morgan PJ, van Beurden E, Beard JR. Perceived sports competence mediates the relationship between childhood motor skill proficiency and adolescent physical activity and fitness: a longitudinal assessment. Int J Behav Nutr Phys Act. 2008;5:40-51; doi: 10.1186/1479-5868-5-40.

19. Venetsanou F, Kambas A, Giannakidou DM, Avloniti A, Draganidis D, Chatzinikolaou A, et al. The validity of two Omron pedometers in preschool children under different conditions. Sylwan. 2015;159(3):60-89.

20. Bruininks R, Bruininks B. Bruininks-Oseretsky Test of Motor Proficiency, $2^{\text {nd }}$ ed. Minneapolis: NCS Pearson; 2005.

21. Venetsanou F, Voukias K, Zavolas G, Mitsios O, Kambas A. Aspects of validity and reliability of the Bruininks-Oseretsky Test of Motor Proficiency - Short Form (BOT-SF) in Greek children. In: Baca A (ed.), Crossing borders through sport science. Proceedings of the $21^{\text {st }}$ Annual Congress of the ECSS. Vienna: University of Vienna; 2016; 427.

22. Harter S, Pike R. The Pictorial Scale of Perceived Competence and Social Acceptance for Young Children. ChildDev.1984;55(6):1969-1982;doi:10.2307/1129772.

23. Makri-Botsari E. How I perceive myself - I [in Greek]. Athens: Ellinika Grammata; 2001.

24. Tudor-Locke C. Taking steps toward increased physical activity: using pedometers to measure and motivate. Pres Counc Phys Fit Sports Res Dig. 2002;3(17):1-8.

25. Craig CL, Tudor-Locke C, Cragg S, Cameron C. Process and treatment of pedometer data collection for youth: the Canadian physical activity levels among youth study. Med Sci Sports Exerc. 2010;42(3):430-435; doi: 10.1249/MSS.0b013e3181b67544.

26. Cohen J. Statistical power analysis for the behavioral sciences, $2^{\text {nd }}$ ed. Mahwah: Lawrence Erlbaum; 1988.

27. Tudor-Locke C, Craig CL, Beets MW, Belton S, Cardon G, Duncan S, et al. How many steps/day are enough? For children and adolescents. Int J Behav Nutr Phys Act. 2011;8:78-91; doi: 10.1186/1479-5868-8-78.

28. Venetsanou F, Kambas A. Motor proficiency in young children: a closer look at potential gender differences.
SAGE Open. 2016;6(1):1-10; doi: 10.1177/21582440 15626226.

29. Hardin M, Greer JD. The influence of gender-role socialization, media use and sports participation on perceptions of gender-appropriate sports. J Sport Behav. 2009;32(2):207-226.

30. Blatchford P, Baines E, Pellegrini A. The social context of school playground games: sex and ethnic differences, and changes over time after entry to junior school. Br J Dev Psychol. 2003;21(4):481-505; doi: 10.1348/ 026151003322535183.

31. Fisher A, Reilly JJ, Kelly LA, Montgomery C, Williamson A, Paton JY, et al. Fundamental movement skills and habitual physical activity in young children. Med Sci Sports Exerc. 2005;37(4):684-688; doi: 10.1249/01. MSS.0000159138.48107.7D.

32. Castelli DM, Valley JA. The relationship of physical fitness and motor competence to physical activity. J Teach Phys Educ. 2007;26(4):358-374; doi: 10.1123/ jtpe.26.4.358.

33. Rutten C, Boen F, Seghers J. Which school- and homebased factors in elementary school-age children predict physical activity and sedentary behavior in secondary school-age children? A prospective cohort study. J Phys Act Health. 2015;12(3):409-417; doi: 10.1123/jpah. 2013-0128.

34. Fox KR, Corbin CB. The physical self-perception profile: development and preliminary validation. J Sport Exerc Psychol. 1989;11(4):408-430; doi: 10.1123/jsep. 11.4.408.

35. Lopes V, Barnett L, Rodrigues L. Is there an association among actual motor competence, perceived motor competence, physical activity, and sedentary behavior in preschool children? J Mot Learn Dev. 2016;4(2):129_ 141; doi: 10.1123/jmld.2015-0012.

36. Spessato BC, Gabbard C, Robinson L, Valentini NC. Body mass index, perceived and actual physical competence: the relationship among young children. Child Care Health Dev. 2013;39(6):845-850; doi: 10.1111/ cch.12014.

37. Liong GH, Ridgers ND, Barnett LM. Associations between skill perceptions and young children's actual fundamental movement skills. Percept Mot Skills. 2015; 120(2):591-603; doi: 10.2466/10.25.PMS.120v18x2.

38. Harter S. Effectance motivation reconsidered. Toward a developmental model. Hum Dev. 1978;21(1):34-64; doi: 10.1159/000271574.

39. Lloyd M, Saunders TJ, Bremer E, Tremblay MS. Longterm importance of fundamental motor skills: a 20-year follow-up study. Adapt Phys Activ Q. 2014;31(1):67-78; doi: 10.1123/apaq:2013-0048.

40. Venetsanou F, Kambas A. Can motor proficiency in preschool age affect physical activity in adolescence? Pediatr Exerc Sci. 2017;29(2):254-259; doi: 10.1123/ pes.2016-0119. 